\title{
The Effects of Health and Wealth Shocks on Retirement Decisions
}

\author{
Dalton Conley and Jason Thompson
}

Both health status and net worth can affect retirement decisions. In some cases, early retirement may be precipitated by a shock to an individual's health and/or economic status. The authors examine how health and wealth shocks affect retirement decisions. They use data from the Panel Study of Income Dynamics to estimate a first-differences model of health and wealth shocks on retirement over the course of the 2000s in the United States. Their results suggest that acute health shocks are associated with labor market exits for older American men but not women. These results appear particularly strong for blacks, whose labor force participation seems particularly sensitive to health status, which may be due to different occupations for blacks and whites. (JEL J26, I12, D91)

Federal Reserve Bank of St. Louis Review, September/October 2013, 95(5), pp. 389-404.

$\mathbf{R}$ etirement decisions both affect and are affected by health status. Health status, in turn, has been linked to net worth. And according to the life cycle model of savings, retirement has an important effect on net worth because retirees begin to expend their assets to maintain consumption once they leave the labor force. Given the multidirectionality of all these influences at this three-factor nexus, it has been difficult to separate the direct impacts of health and wealth on retirement from the reciprocal effect of retirement on health and wealth. This is our goal in the present article.

Many studies have found that health shocks predict retirement decisions (see, e.g., Hagan, Jones, and Rice, 2009). For example, using fixed effects estimators and instrumenting subjective health by "health stock," Disney, Emmerson, and Wakefield (2006) find that ill health strongly predicts early retirement among respondents older than 50 years of age in the British Household Panel Survey. Health limitations have also been shown to have a similar impact on early retirement decisions. However, the evidence does not completely support the claim that health shocks lead to exit from the labor force. For example, French (2005) finds that health is not among the more important determinants of job exit at older ages.

Dalton Conley is university professor at New York University and a research associate at the National Bureau of Economic Research. Jason Thompson is a graduate student in the department of sociology at New York University. This paper was prepared for presentation at the symposium, "Restoring Household Financial Stability after the Great Recession: Why Household Balance Sheets Matter," sponsored by the Federal Reserve Bank of St. Louis and Washington University in St. Louis, February 5-7, 2013.

(c) 2013, The Federal Reserve Bank of St. Louis. The views expressed in this article are those of the author(s) and do not necessarily reflect the views of the Federal Reserve System, the Board of Governors, or the regional Federal Reserve Banks. Articles may be reprinted, reproduced, published, distributed, displayed, and transmitted in their entirety if copyright notice, author name(s), and full citation are included. Abstracts, synopses, and other derivative works may be made only with prior written permission of the Federal Reserve Bank of St. Louis. 


\section{Conley and Thompson}

In addition to this ambiguity, we also know that retirement may adversely affect health. U.K. panel data have been marshaled to show that labor force participation has a gender-specific effect on health. Specifically, ongoing labor force participation is detrimental to male health but positive for female health (Cai, 2010). However, the evidence is more consistent in the United States: Thanks to the natural experiment of the Social Security notch, which applies to individuals born between 1917 and 1921, we know that retirement is not good for the health of septuagenarians. Specifically, individuals born before January 1, 1918, received lower Social Security benefits compared with their counterparts born on January 1, 1918, and thereafter. Lower payments resulted from a 1977 correction of a previous flawed calculation. 1 On average, those who received the higher payments thanks to a change in cost-of-living indexing during the 1970s left the labor force earlier than those who received the lower payments. However, despite the greater transfer income, Snyder and Evans (2006) found that those who retired earlier had a shorter life expectancy.

Meanwhile, just as health shocks can affect an individual's decision to continue working, so also can financial shocks. In addition to unexpected job loss, other shocks to individual net worth include investment performance, unexpected costs, family transitions (such as divorce), or other dynamics such as tax law changes. According to economic theory, smoothing consumption over the life course would require a delay in retirement when a negative shock to retirement savings occurs, just as a positive shock would allow an early exit from the labor market. $\underline{2}$

Indeed, empirical research has consistently found a positive wealth effect on retirement exits from the labor market. Both higher annuity rates and/or stock prices lead to a greater probability of retirement (Zucchelli et al., 2010). Using data from the Health and Retirement Study, Coronado and Perozek (2003) found that "respondents who held corporate equity immediately prior to the bull market of the 1990s retired, on average, 7 months earlier than other respondents." House prices also seem to affect the exit decision in the same direction (Zucchelli et al., 2010, and Goodstein, 2008). Using changing stock or housing prices or interest rates (which, in turn, affect annuity payouts) as factors affecting retirement decisions is useful but may confound other effects. That is, when the entire stock market goes up or down, such movement affects perceptions of future wealth. The positive effect of higher wealth may be partially offset by rising expectations for the trend to continue, thus causing individuals to remain in the labor force to "grow" their nest egg more before they begin to draw it down or convert it into a retirement income stream. In addition, when markets are rising or falling, they are doing so for everyone, thereby changing individuals' calculations about their potential relative standard of living in retirement. That is, they may feel richer-but not as rich as they might have felt had their own stocks risen while the rest of the market was stable or falling. Relative comparisons may be at work in the retirement decision arena and affect decisionmaking.

Another approach uses receipt of an inheritance as the instrumental variable for retirement decisions to address these concerns. One in five households with older workers in the Health and Retirement Study receive an inheritance over an 8-year period. The median value of such a bequest is $\$ 30,000$. Brown, Coile, and Weisbenner (2010) find that (i) receipt of an inheritance increases the probability of retirement by 12 percent and (ii) the effect is even larger when the inheritance is "unexpected." Their article provides a nice confirmation of the wealth effects iden- 
tified using stock markets (also see Goodstein, 2008). However, it too suffers from some limitations-namely, the receipt of an inheritance may have other retirement-inducing effects that may bias the estimate of the wealth effect. The death of the close relative or friend who provided the bequest, for example, may induce an individual to reconsider life priorities or confront the finiteness of the life span, which may instigate an earlier exit from the labor force to enjoy "the good life." Similarly, the inheritance-related death may require rearrangement of family responsibilities and a shift from paid labor to unpaid caretaking work.

In this study, we build on existing work by combining the two strands of research previously discussed: We examine the relationship between health shocks and wealth shocks, on the one hand, and retirement decisions, on the other. There is ample reason to suspect that wealth shocks may be heterogeneous based on an individual's health characteristics. That is, if an individual is ailing and experiences a rise in wealth, the increase may remove a budget constraint and allow an exit from the labor market. However, the effect of positive wealth shocks may be lessened for those in good health who can continue to work without significantly depleting their health capital (Grossman, 1972). Thus, we use data from the Panel Study of Income Dynamics (PSID) to estimate a first-differences model of health and wealth shocks on retirement over the course of the 2000s in the United States. For the reasons discussed previously, we do not instrument wealth shocks from inheritance (though we do estimate the impact of inheritance receipt in the model directly), nor do we distinguish between idiosyncratic wealth shocks and those related to the markets as a whole.

To preview our findings, our models show that negative health shocks do lead to a greater probability of retirement, as do positive shocks to net worth. Both of these effects are strongest for men and insignificant for women, who show weaker labor elasticities. Further, the Great Recession led to a wave of retirements-net of other factors-but this effect was not moderated by asset levels or health. Meanwhile, wealth is affected by health shocks but the effects differ for blacks and whites.

\section{DATA AND METHODS}

The PSID originated in 1968 with a nationally representative sample of 5,000 American families and has followed the economic and health histories of individuals. As the longest-running longitudinal study on family and individual dynamics, the study design is too complex to detail completely here (see Hill, 1992, or Duncan and Hill, 1989, for fuller descriptions). We construct an unbalanced panel of data collected biennially from 1999 through 2009 to examine the role of health in retirement decisions and subsequent changes in wealth. $\frac{3}{3}$ We truncate this sample to black and white $\underline{4}$ adult respondents 40 to 70 years of age in 1999 who were the head, wife, or cohabitating partner of their household in any years between 1999 and 2009. Because wealth is measured at the family level, all respondents must be a head, wife, or cohabitating partner for all years in which they are included in the sample. If a respondent were to be included in the sample but no longer as a head of the family, the wealth measure for that respondent would be for the new household to which the individual moved. This methodology might incorrectly assign resources to the individual that are not, in actuality, under the individual's management. 


\section{Conley and Thompson}

The random selection of one adult head 5 in the family was a careful decision on our part. Given the propensity for the male adult in a family to be labeled the head of the household, selecting only heads of households for analysis would potentially bias results. Illness of either head is likely to relate with changes in labor force participation (Bound et al., 1999; Charles, 1999; Wu, 2003) and changes in wealth. Therefore, we run analyses on the full sample and separated by gender.

\section{Key Variables}

Retirement. Our primary dependent variable is a measure coded " 1 " if the individual is currently retired. Just over 6 percent of person-waves represent transitions into retirement. However, in 2.73 percent of person-waves, individuals move in the opposite direction-out of retirement and back into the labor force. For this reason, we model this situation using an ordered logit regression when retirement is our left-hand-side variable.

Total Family Wealth. $\frac{6}{}$ This variable is from the 1999, 2001, 2003, 2005, 2007, and 2009 waves of the PSID. The PSID codes family wealth by summing the total assets, minus debts, that a family owns. Wealth is calculated by adding the values of a family business or farm, checking and savings accounts, real estate other than the main home, stocks and mutual funds, vehicles, bonds and life insurance policies, individual retirement accounts and annuities, and home equity, minus any debts.

As is common with monetary variables, the distribution of wealth is highly skewed in the sample. We perform an inverse hyperbolic sine (IHS) transformation to correct for this skewness. A $\log$ transformation of the wealth variable would also address the issue of non-normality of the dependent variable. However, log transformations do not allow zero or negative values, which are common in data concerning wealth. The IHS transformation addresses the issue of extreme values while allowing positive, zero, and negative values for our wealth variable (for more detail, see Burbidge, Magee, and Robb, 1988; MacKinnon and Magee, 1990; and Pence, 2006). .7 As outlined in detail by Burbidge, Magee, and Robb (1988), the IHS transformation has been used for data pertaining to wealth and health expenditures (Pence, 2006, and Zhang et al., 2000), $\underline{8}$ specifically when variables take both extreme positive and negative values and, in many cases, the value of zero. Given the potential for negative income coded in the PSID, we also transform the family income variable. $\underline{9}$ The key right-hand-side variables for regression models predicting changes in wealth include dummy variables for marital status (" 1 " for married), unemployment ("1" for currently unemployed), onset of acute illness or chronic illness, and total family income.

Family Income. We smooth income by using a 5-year average leading up to each wave to account for potential idiosyncratic fluctuations. Since income may have zero or negative values, we use the IHS transformation for this variable.

Acute Health Shock and Chronic Health Condition. In the past six published waves of data (1999-2009), the PSID codes for the incidence of 13 health conditions for the head of household and wife. We construct two variables to distinguish severe acute health shocks from the onset of chronic conditions. We classify the occurrence of a stroke, heart attack, heart disease, lung disease, or cancer $\underline{10}$ as acute health shocks. We include asthma, arthritis, diabetes, high blood pressure, learning disabilities, memory loss, psychiatric disorders, and "other" chronic 
illnesses in the indicator (a PSID-created miscellaneous category) for chronic health conditions. Each of these indicator variables is coded " 1 " if an acute or chronic illness occurred over the course of each wave. Unfortunately, the PSID data do not allow us to determine precise dates for the onset of chronic illnesses and recovery for each individual. Given that the PSID does not code the precise date on which an individual recovered from a particular illness, we code each year as " 1 " following the initial onset of a chronic illness under the rationale that such conditions have lingering effects across many waves.

With our first-differences methodology, indicators for gender and race are de facto factored out and age drops from equations as each respondent ages 2 years across waves. We chose to omit education from the models as most individuals have completed their formal education by age 40. Table 1 presents descriptive statistics.

\section{STATISTICAL APPROACH}

All regression models implement a first-differences identification strategy. We implement the first-differences approach to factor out all unobserved, time-constant variables that may relate to retirement decisions. Our first analysis, the influence of the onset of acute and chronic illnesses on retirement decisions, implements ordered logit regression of retirement on changes in health, marriage, and IHS-transformed family wealth. We also model these regressions separately for male and female household heads. To analyze the relationship among health, retirement decisions, and subsequent changes in wealth, we regress separate models for the change in family wealth on the concurrent and lagged changes in family income, marriage, unemployment, retirement, health shocks, and an interaction between acute health shocks and retirement.

\section{RESULTS}

Table 2 presents results of first-differences ordered logit regressions of changes in retirement status on acute health shocks, the onset of chronic health conditions, marriage status, and IHStransformed total family wealth. Models 1 through 3 regress changes in retirement status on changes in each category of health for the full sample, black respondents, and white respondents, respectively. Without separating the models by gender, it appears that acute health shocks hold little significance in predicting retirement. The experience of an acute shock is significant for only black individuals, with approximately a 56 percent $[\exp (0.443)]$ increase in the likelihood of retirement within the same wave. This finding remains when adding controls for changes in marital status and IHS-transformed total family wealth in models 4 through 9 . While family wealth itself is not significant in predicting labor market entries, the 2009 indicator variable is significant and positive, suggesting that-ceteris paribus-the Great Recession led many older Americans to permanently leave the labor force.

When we separate the sample by gender, however, the relationship between acute health shocks and retirement becomes much clearer. In Table 3, we run the same analyses for only males. Models 1 through 3 regress changes in retirement status for males on the onset of acute health 


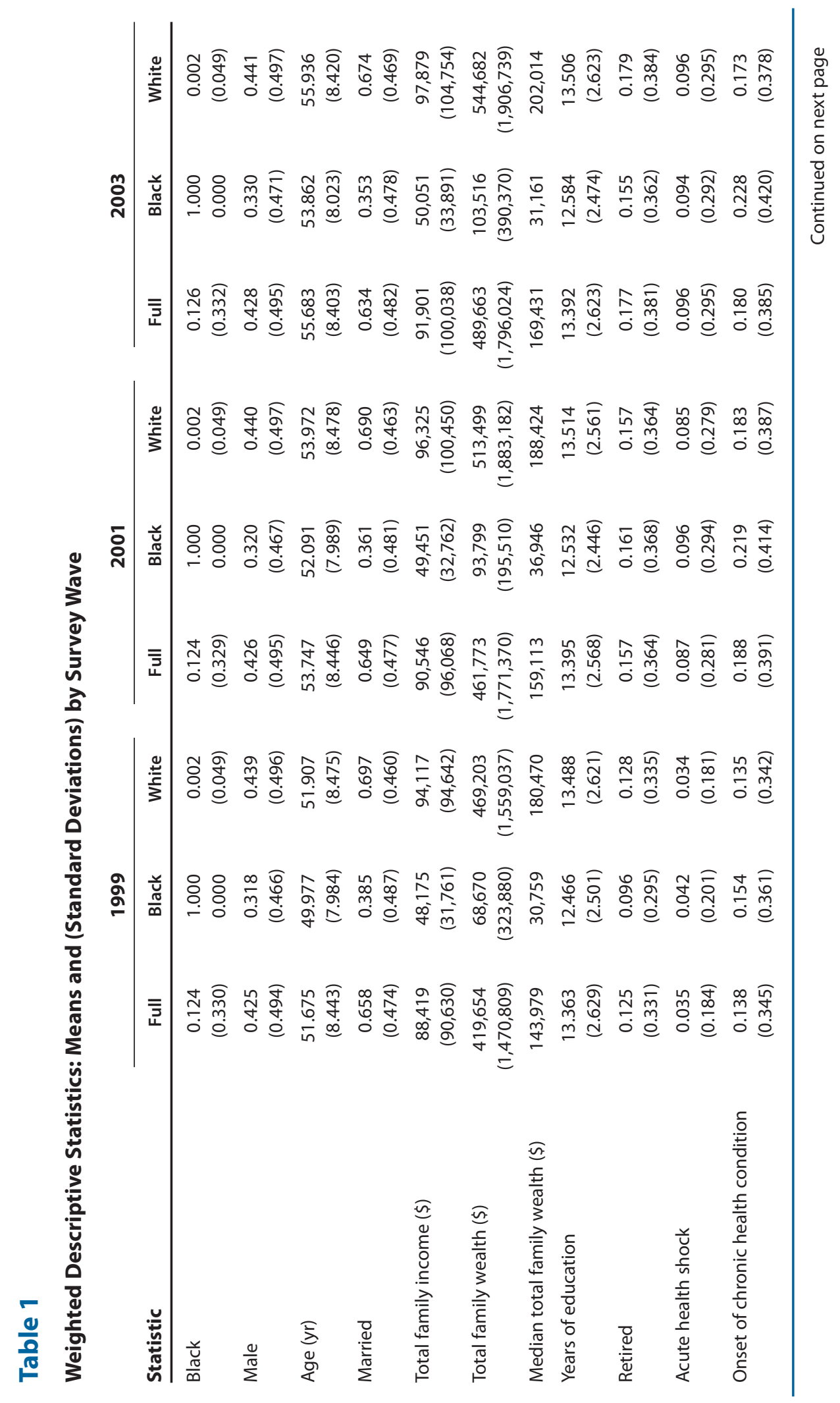


Conley and Thompson

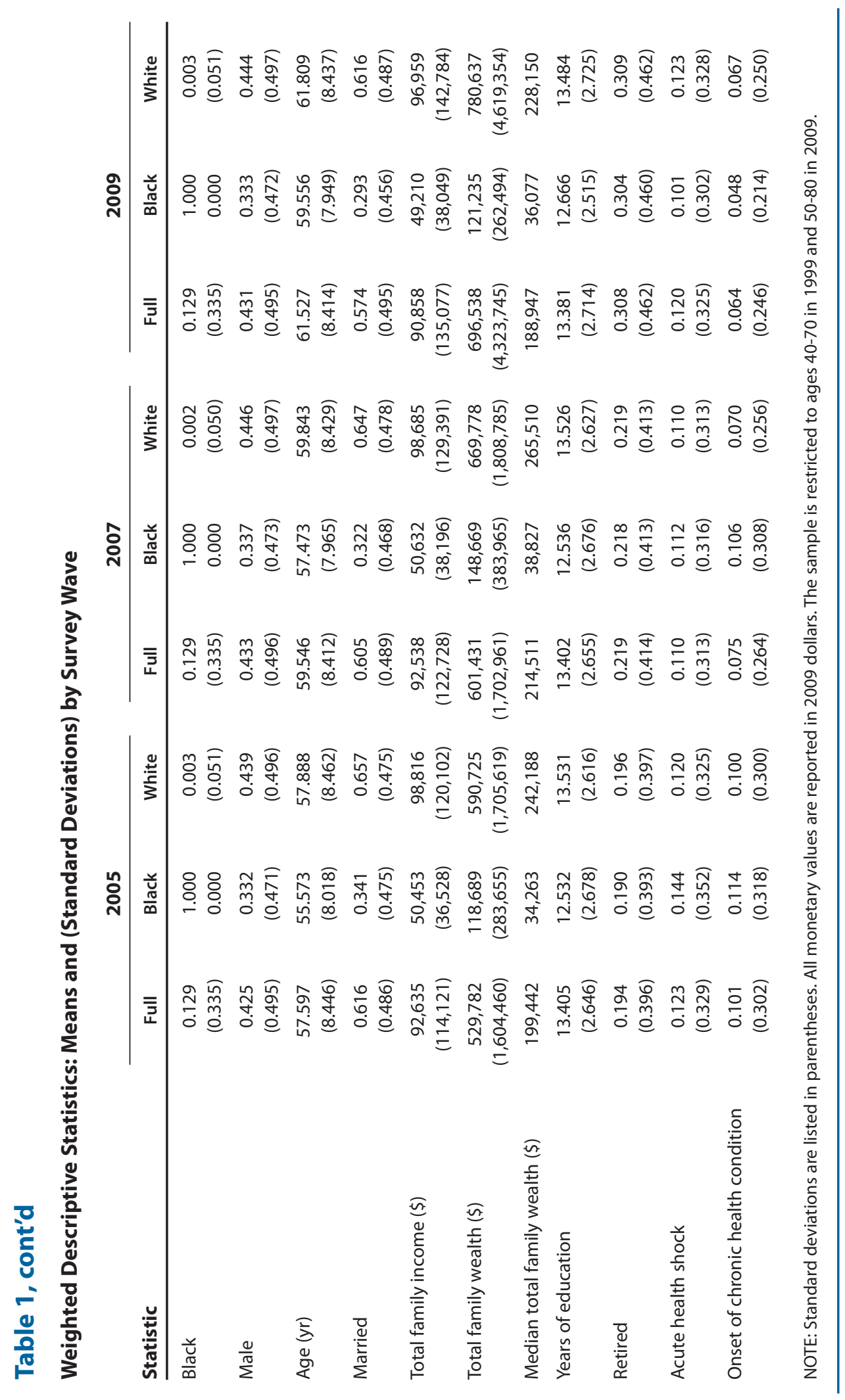




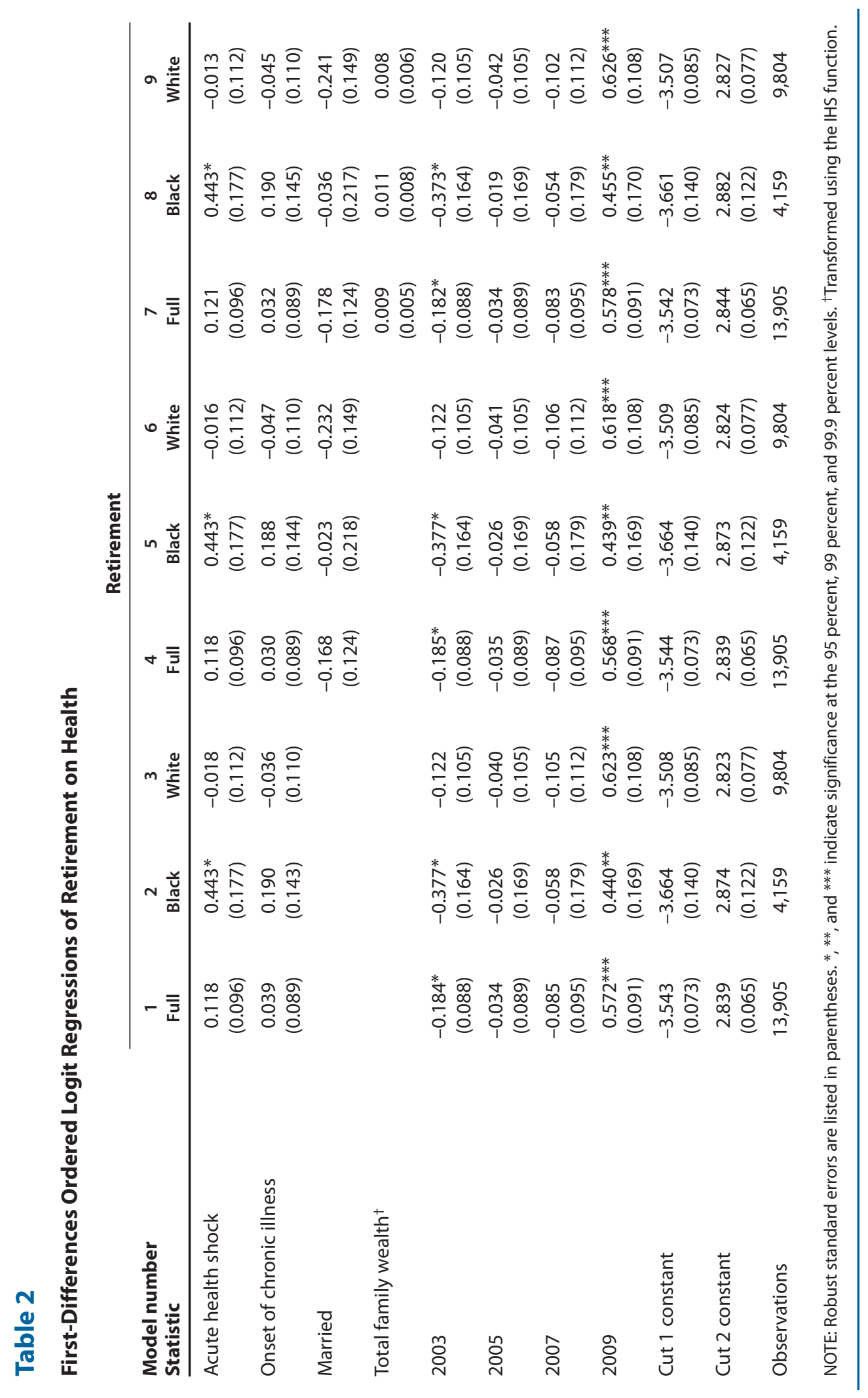




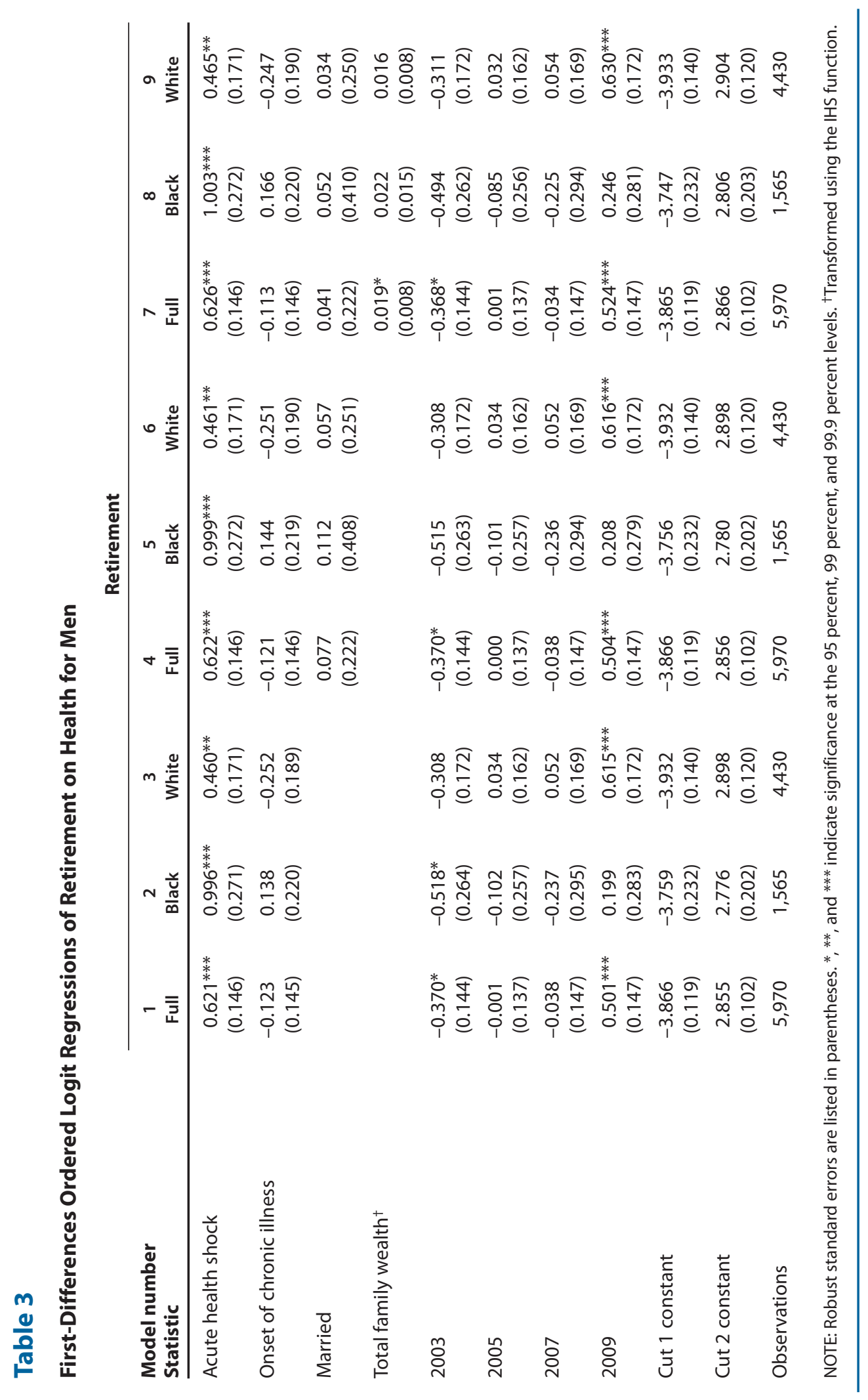




\section{Conley and Thompson}

shocks and chronic health conditions for all males, black males, and white males, respectively. Models 4 through 6 and 7 through 9 take the same pattern, adding controls for changes in marital status and total family wealth. The findings in models 1 through 3 remain significant across the remaining models. Controlling for changes in wealth, marital status, and the onset of chronic conditions, acute health shocks significantly predict retirement for both black and white males. In models 8 and 9 we see that black males with an acute health shock are 2.73 times [exp(1.003)] more likely to retire, while white males are 1.59 times $[\exp (0.465)]$ more likely to retire following the onset of an acute illness. Family wealth increases are also associated with labor market exits in model 7, but not for whites and blacks separately when we split the sample by race. Finally, 2009 is again associated with increased labor market exits net of other factors.

The high significance of acute illness in predicting retirement for males mostly vanishes for females. Models 1 through 3 in Table 4 show the results of regressing change in retirement status on health changes for all females in our sample and females separated by race. Counterintuitively, model 3 shows that the experience of an acute health shock is negatively associated with white females' decisions to retire within the same wave. With controls for changes in marital status and changes in total family wealth in models 4 through 9 , the experience of an acute health shock remains significant. In model 9, an acute health shock relates to a 27 percent $[1-\exp (-0.317)]$ decrease in the likelihood of retirement for white females. Further, family wealth has no effect. Finally, women also permanently left the labor force in greater numbers between 2007 and 2009, holding other factors constant. When we tested interaction effects-for example, between acute illness onset and wealth levels or between survey wave 2009 and either health or wealth -we were surprised to find that such effects were not significant.

With findings suggesting that acute health shocks play a significant role in retirement decisions, we next analyze whether health shocks for retired individuals have a differential impact on wealth than for those still in the workforce. We run two analyses, one for concurrent changes in wealth and one for changes in wealth in the subsequent wave as acute health shocks and retirement may relate to short-term changes within the wave or over the next wave as retirees begin to spend down accumulated wealth. Table 5 presents the first-differences ordinary least squares (OLS) regressions of changes in IHS-transformed total family wealth on key independent variables. Model 1 of Table 5 presents results for the full sample regression of changes in IHStransformed total family wealth on changes in IHS-transformed total family income, marital status, unemployment status, and retirement status. Models 2 and 3 present these regressions

separated by race. Subsequent models follow the same pattern and add controls for changes in health status. In models 1 through 6, we do not find any significant effect of retirement on wealth in the same wave. However, when we interact retirement status with acute health shocks in models 7 through 9, significant results appear. Model 8 presents the interaction term between an acute health shock and retirement for black individuals. The significant coefficient suggests that the onset of an acute illness for retired black individuals drains total family wealth more than for nonretired black individuals. We present only the results for the full sample (males and females combined) as separating by gender fails to produce any significant results.

Table 6 presents the same analysis as Table 5 but with one-wave lags on all independent variables to examine how changes in health and retirement are associated with changes in wealth 
Conley and Thompson

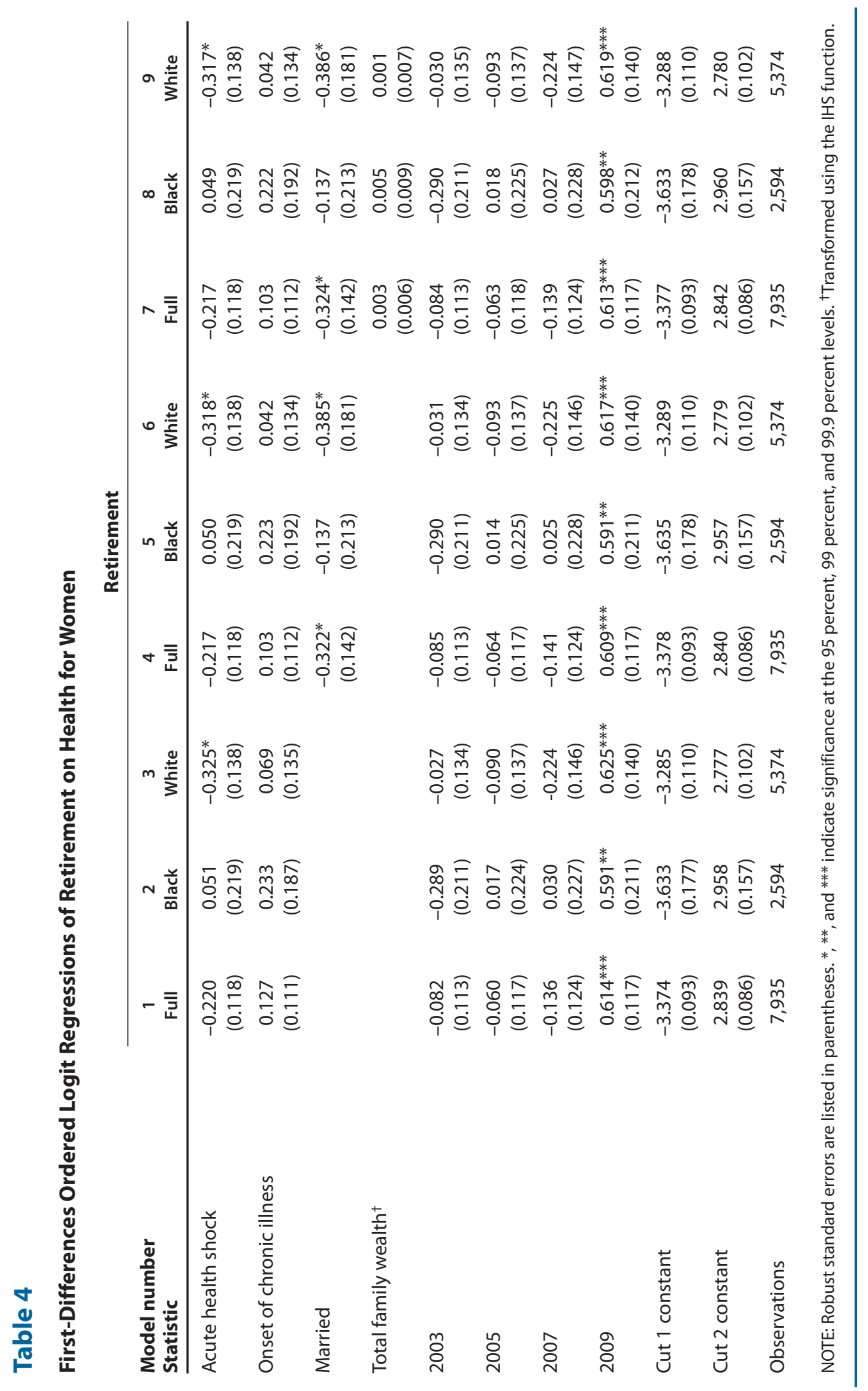




\section{Conley and Thompson}

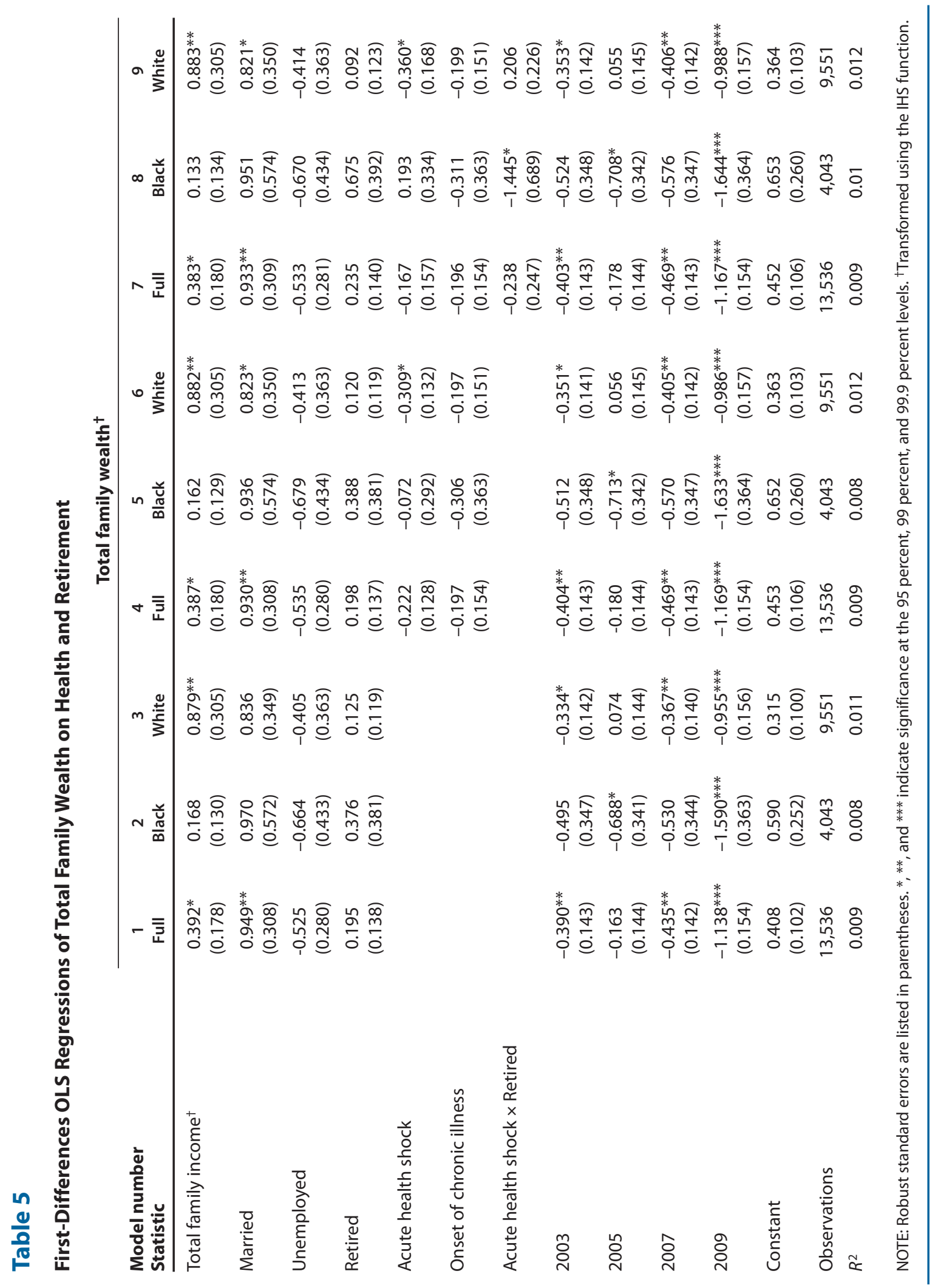




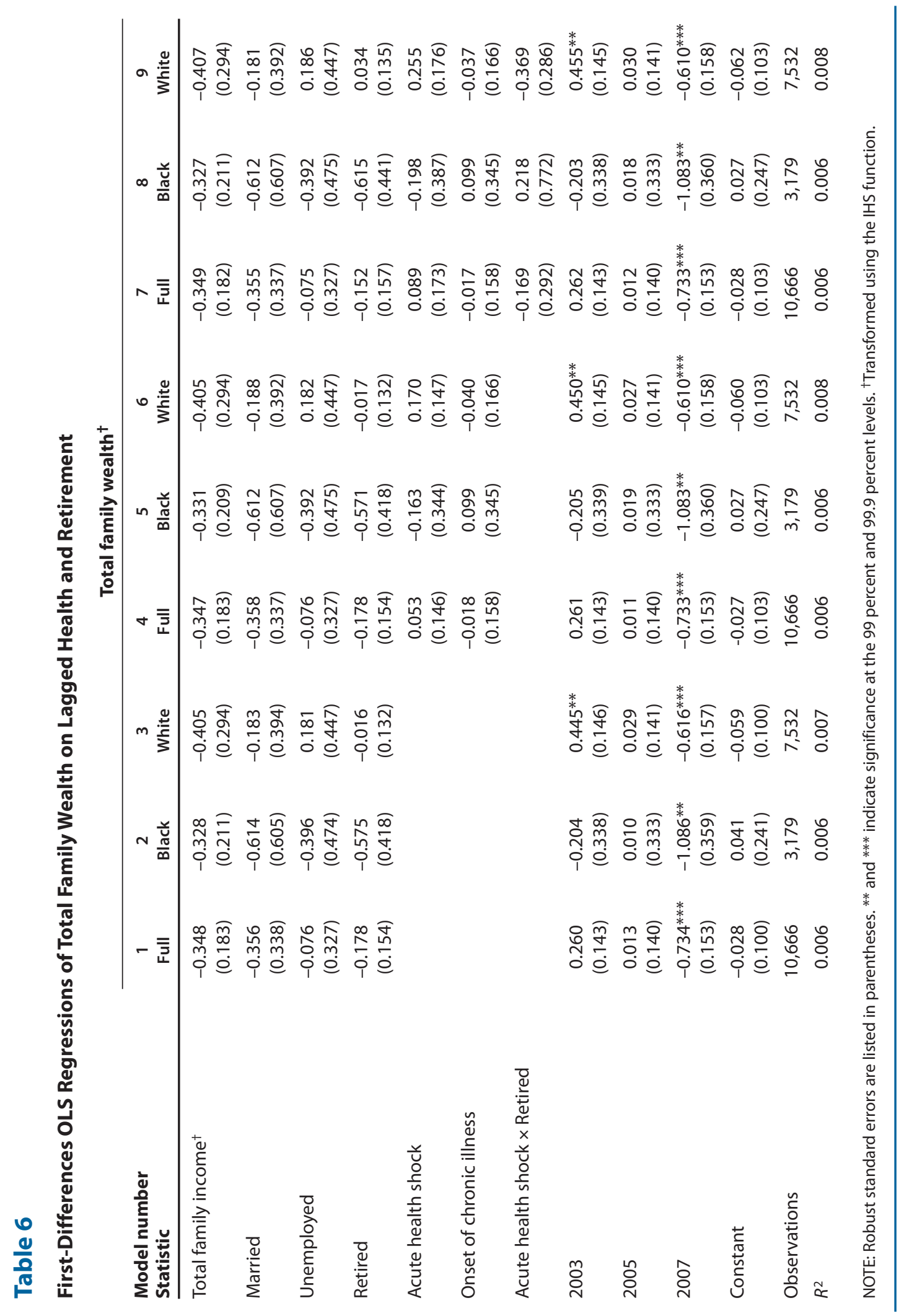




\section{Conley and Thompson}

over the next wave. Across all models, it appears that retirement and changes in health are not associated with changes in wealth over the next wave. Furthermore, the interaction between retirement and an acute health shock proves insignificant. Again, we present results for only the full sample because results are insignificant when the sample is split by gender.

\section{DISCUSSION}

Our results suggest that acute health shocks are associated with labor market exits for older American men but not women. These results appear particularly strong for blacks, whose labor force participation seems particularly sensitive to health status, which may be due to different occupations for blacks and whites. Perhaps, for instance, black men tend to work in industries and occupations that are more physically demanding, while white men are disproportionately employed in sedentary jobs and can withstand a health limitation. It could also be that other aspects of the job-such as benefits and medical leave policies-are important. Meanwhile, increases in family wealth between waves allow men to retire, but they have no effect on women. This lower female labor market elasticity may be due to the fact that women may be more economically vulnerable when they are the sole householder; conversely, women may be less critically responsive to family economic conditions when they are secondary earners.

It is also important to note that net of all these conditions-as well as income and marital status-2009 marked a huge exodus from the labor market for this sample. While the size of this labor market exit may be no surprise for those familiar with the fallout from the Great Recession, it is interesting to note that this effect (i) holds net of changes in income, health, and wealth and (ii) is not moderated by health shocks or wealth. In other words, all groups of individuals who left the labor market in greater numbers during the Great Recession did so regardless of their asset cushion or health status. Meanwhile, in our prediction of family net worth based on retirement status and health shocks, we find no significant effects regardless of whether we lag the right-hand-side measures-with two notable exceptions. For whites, it appears that net of labor market status and other factors, acute health shocks lower net worth contemporaneously (but not lagged). However, for blacks this effect is conditional on retirement status. Retirement alone does not affect the net worths of blacks, nor do health shocks alone. However, blacks suffer a wealth hit when they are retired and are struck by an acute medical condition. This may suggest that different occupational sectors or other factors lead to different exit pathways from the labor market for blacks and whites affected by health problems.

\section{CONCLUSION}

In some cases, early retirement may be precipitated by a shock to an individual's health status. We use data from the Panel Study of Income Dynamics to examine how health shocks and wealth shocks affect retirement decisions over the course of the 2000s in the United States using a first-differences model. We find that acute health shocks are associated with early labor market

exits for older American men but not women. These results appear particularly strong for blacks, whose labor force participation seems particularly sensitive to health status. 


\section{NOTES}

1 For more information, see "The'Notch'Provision" (http://www.ssa.gov/pubs/EN-05-10042.pdf).

$\underline{2}$ This prediction is very straightforward in contrast to, say, the effect of a change in earnings. If wages rise, then so do savings, indirectly leading to a positive income effect on the consumption of leisure (in the form of retirement). However, the substitution effect works in the opposite direction; higher wages make exits from the labor market more expensive in terms of opportunity cost. Of course, if potential pension income increases thanks to government policy or a change in the annuity rate, then this gain is more akin to a wealth shock than an earnings change.

3 We also ran regressions on all years that included data on family wealth $(1984,1989,1994,1999,2001,2003,2005$, 2007, and 2009) with similarly constructed variables; results did not significantly change. We chose to present the results for the analysis over the period of the PSID where health and wealth were measured consistently at 2-year intervals to avoid the complication of differing time intervals between waves.

4 Sample numbers were too small for further comparisons across racial groups.

$\underline{5}$ The PSID enumerates heads and wives/cohabitating partners. For simplicity purposes, we refer to either of the household heads as a head of the family. Therefore, the random selection of one adult head includes male and female "heads," "wives," or "cohabiters."

$\underline{6}$ The PSID offers many measurements of wealth, including the aggregated values of total family wealth with home equity and total family wealth without home equity. Given the potential for measurement error in individuals estimating the value of their home, we ran all analyses with and without home equity included to determine whether results were sensitive to the inclusion of home equity. Results were not significantly altered.

7 We also conducted regressions using log-transformed wealth variables with no significant change in results.

$\underline{8}$ For details on the IHS transformation and analyses supporting its use versus other transformations, see Burbidge, Magee, and Robb (1988).

9 We also conducted all analyses using log-transformed family income without significant change in our regression results.

10 Our definition of "acute" health shocks largely mirrors definitions of "severe" illnesses in other studies (Smith, 2007). The inclusion of cancer in the acute category is potentially misleading, as some forms of cancer may not come as a "shock" to health given certain individual behaviors. However, our findings are robust to alternative definitions of acute illness that do not include the onset of cancer.

\section{REFERENCES}

Bound, John; Schoenbaum, Michael; Stinebrickner, Todd R. and Waidmann, Timothy. "The Dynamic Effects of Health on the Labor Force Transitions of Older Workers." Labour Economics, June 1999, 6(2), pp. 179-202.

Brown, Jeffrey R.; Coile, Courtney C. and Weisbenner, Scott J. "The Effect of Inheritance Receipt on Retirement." Review of Economics and Statistics, May 2010, 92(2), pp. 425-34.

Burbidge, John B.; Magee, Lonnie and Robb, A. Leslie. "Alternative Transformations to Handle Extreme Values of the Dependent Variable." Journal of the American Statistical Association, March 1988, 83(401), pp. 123-27.

Cai, Lixin. "The Relationship Between Health and Labour Force Participation: Evidence from a Panel Data Simultaneous Equation Model." Labour Economics, January 2010, 17(1), pp. 77-90.

Charles, Kerwin K. "Sickness in the Family: Health Shocks and Spousal Labor Supply." Working Paper No. 00-011, Ford School of Public Policy, University of Michigan, August 1999; http://www.fordschool.umich.edu/research/papers/PDFfiles/00-011.pdf.

Coronado, Julia L. and Perozek, Maria. "Wealth Effects and the Consumption of Leisure: Retirement Decisions during the Stock Market Boom of the 1990s." Finance and Economics Discussion Series No. 2003-20; Board of Governors of the Federal Reserve System, May 2003; http://www.federalreserve.gov/pubs/feds/2003/200320/200320pap.pdf.

Disney, Richard; Emmerson, Carl and Wakefield, Matthew. "IIl Health and Retirement in Britain: A Panel Data-Based Analysis." Journal of Health Economics, July 2006, 25(4), pp. 621-49. 


\section{Conley and Thompson}

Duncan, Greg J. and Hill, Daniel. "Assessing the Quality of Household Panel Survey Data: The Case of the Panel Study of Income Dynamics." Journal of Business and Economic Statistics, October 1989, 7(4), pp. 441-51.

French, Eric. "The Effects of Health, Wealth, and Wages on Labour Supply and Retirement Behaviour." Review of Economic Studies, April 2005, 72(2), pp. 395-427.

Goodstein, Ryan. "The Effect of Wealth on Labor Force Participation of Older Men." Ph. D. Dissertation, University of North Carolina at Chapel Hill, 2008.

Grossman, Michael. "On the Concept of Health Capital and the Demand for Health." Journal of Political Economy, March-April 1972, 80(2), pp. 223-55; doi:10.1086/259880.

Hagan, Ronald; Jones, Andrew M. and Rice, Nigel. (2009). "Health and Retirement in Europe." International Journal of Environmental Research and Public Health, October 2009, 6(10), pp. 2676-95.

Hill, Martha S. The Panel Study of Income Dynamics: A User's Guide. Newbury Park, CA: Sage Publications, 1992.

MacKinnon, James G. and Magee, Lonnie. "Transforming the Dependent Variable in Regression Models." International Economic Review, May 1990, 31(2), pp. 315-39.

Pence, Karen. "The Role of Wealth Transformations: An Application to Estimating the Effect of Tax Incentives on Saving." B.E. Journal of Economic Analysis \& Policy, 2006, 5(1), pp. 1-26.

Smith, James P. "The Impact of Socioeconomic Status on Health Over the Life-Course." Journal of Human Resources, Fall 2007, 42(4), pp. 739-64.

Snyder, Stephen E. and Evans, William N. "The Effect of Income on Mortality: Evidence from the Social Security Notch." Review of Economics and Statistics, August 2006, 88(3), pp. 482-95.

Wu, Stephen. "The Effects of Health Events on the Economic Status of Married Couples." Journal of Human Resources, Winter 2003, 38(1), pp. 219-30.

Zhang, Mingliang; Fortney, John C.; Tilford, John M. and Rost, Kathryn M. "An Application of the Inverse Hyperbolic Sine Transformation-A Note." Health Services and Outcomes Research Methodology, June 2000, 1(2), pp. 165-71.

Zucchelli, Eugenio; Jones, Andew M.; Rice, Nigel and Harris, Anthony. "The Effects of Health Shocks on Labour Market Exits: Evidence from the HILDA Survey." Australian Journal of Labour Economics, 2010, 13(2), pp. 191-218. 